
(Nature 452, 935-936; 2008).

\section{European research system must not go bananas}

SIR — Luke Georghiou's Commentary may be applauded by science policy-makers, but it sent shivers down my spine as a scientist. Curiosity-driven research is under siege from those who claim that they know best how to "attain Europe's economic, social and environmental goals", and to "engage research with the problems that society recognizes as central".

There is nothing apparently wrong with such clichés, but for me they evoked an image of a tribe of chimpanzees sitting in banana trees pondering their societal needs. The issue at stake is to find a better technology for banana peeling. To climb down the tree and start walking would be viewed by the group as either a priority or politically correct. Likewise, the Commentary is full of populist, politically correct goals such as carbon capture, and leaves aside difficult ones such as nuclear energy.

This could not be further removed from the message of another Commentary 'The unpaid debt' (Nature Phys. 3, 824-825; 2007). That described how the fundamental research that usually serves - let's face it very obscure goals can nevertheless "yield unforeseen benefits of great value for society". Fortunately, there are still some agencies and a few politicians who do their best to fund blue-sky, seemingly useless research - but they are under attack.

Nature is uniquely placed to help them by conveying the message that a successful society must commit a significant portion of its resources to curiosity-driven research and not ask for anything apparently useful in return, as long as it is assured that qualified people do the work. Otherwise, we shall never learn how to climb down those banana trees that are undisputedly important and recognizable to society.

\section{Andre Geim Centre for Mesoscience} and Nanotechnology, University of Manchester, Oxford Road, Manchester M13 9PL, UK

\section{Large projects can create useful partnerships}

SIR — Luke Georghiou urges reforms to the European Commission's research system, criticizing the present Framework Programmes for their many small and very loosely connected projects.

The large integrated projects of the Sixth Framework Programme are a notable exception. These include the ALARM project, intended to assess large-scale environmental risks for biodiversity using tested methods (www. alarmproject.net). This encompasses 68 partner organizations, with some 250 participants from 35 different countries. It focuses on the combined risks derived from climate change, environmental chemicals, biological invasions and pollinator loss against their socio-economic background.

Such large projects within the Framework Programmes offer opportunities for productive partnerships. It may look like locking scientists in a room and expecting them to get along which Paul Jeffrey is quoted as saying won't happen, in the related News Feature 'With all good intentions' (Nature 452, 682-684; 2008). But our experience in ALARM is that, if you give scientists sufficient choice, new and productive partnerships emerge, and their success increases with project size and collaboration options.

The consortium agreements required in the Sixth Framework Programme's integrated projects fit the model agreements you refer to in your Editorial on the subject, 'The path to productive partnerships' (Nature 452, 665; 2008). For ALARM, they were signed by all partners before the project started. Laying down rules may seem unnecessary as members cooperate to avoid adverse consequences. But this may be different without such rules.

We therefore disagree with Georghiou's view that the Framework Programmes have to go. We favour more projects of variable sizes, organized through work plans and accompanied by model agreements - including a reasonable proportion of large integrated projects to create opportunities for interdisciplinary and productive partnerships.

Josef Settele, Joachim Spangenberg, Ingolf Kühn UFZ, Helmholtz Centre for Environmental Research, Theodor-Lieser-Strasse 4, 06120 Halle, Germany

\section{European research needs a dash of anarchy}

SIR - As Luke Georghiou urges, 'Europe's research system must change' - but most certainly not in the direction he proposes. He wants to strengthen strategic and applied research within the EU Framework Programme, advocating direct political influence on research into "problems that society recognizes as central" by creating even larger directed research programmes than we have now. But problems can arise from forced collaborations and top-to-bottom direction in large research consortia, as your recent Editorial and News Feature on the subject make clear (Nature 452, 665 and 682-684; 2008).

Almost every significant breakthrough in the history of science has come about by serendipity - not as a result of strategic planning or problemoriented and directed research. To foster real innovation in Europe's science, he should be advocating bottom-up research by small and innovative groups.

Young investigators, even those with brilliant ideas and a novel approach, are unlikely to be invited to participate in huge directed consortia. These mostly involve laboratories that have already established their name and fame, and are now often comfortably operating on well-worn tracks or working opportunistically on headlinegrabbing problems or fashionable topics.

Science and innovation are chaotic, stochastic processes that cannot be governed and controlled by desk-bound planners and politicians, whatever their intentions. Good scientists are by definition anarchists, who don't want to be managed by what Gottfried Schatz of Biocenter Basel calls 'chronoclasts' - people whose bureaucracy steals their research time and blunts their creative potential. Good science has an inherent potential for selforganization.

Let's have non-bureaucratic generous research support for the broadest possible palette of basic science problems. That is what would change Europe's research system for the better.

Theo Wallimann Institute of Cell Biology, ETH Zurich, Hoenggerberg, HPM D24.1, Schafmattstrasse 18, 8093 Zurich, Switzerland 